\title{
A Method for retrieving Endodontic or Atypical Nonendodontic separated Instruments from the Root Canal: A Report of Two Cases
}

\author{
${ }^{1}$ Jardel Camilo do Carmo Monteiro, ${ }^{2}$ Milton Carlos Kuga, ${ }^{3}$ Andrea Abi Rached Dantas \\ ${ }^{4}$ Keren Cristina Fagundes Jordão-Basso, ${ }^{5}$ Katia Cristina Keine, ${ }^{6}$ Prashant Jay Ruchaya \\ ${ }^{7}$ Gisele Faria, ${ }^{8}$ Renato de Toledo Leonardo
}

\begin{abstract}
Aim: This clinical report presents a new method for retrieving separated instruments from the root canal with minimally invasive procedures.
\end{abstract}

Background: The presence of separated instrument in root canal may interfere in the endodontic treatment prognosis. There are several recommended methods to retrieve separated instruments, but some are difficult in clinically practice.

Case report: This study describes two cases of separated instrument removal from the root canal using a stainless-steel prepared needle associated with a K-file. Case 1 presented a fractured gutta-percha condenser within the mandibular second premolar, it was separated during incorrect intracanal medication calcium hydroxide placement. Case 2 had a fractured sewing needle within the upper central incisor that the patient used to remove food debris from the root canal. After cervical preparation, the fractured instruments were fitted inside a prepared needle and then an endodontic instrument (\#25 K-file) was adapted with clockwise turning motion between the needle inner wall and the fragment.

Conclusion: The endodontic or atypical nonendodontic separated instrument may be easily pull on of the root canal using a single and low cost device.

Clinical significance: The methods for retrieving separated instruments from root canal are difficult and destructive procedures. The present case describes a simple method to solve this problem.

\footnotetext{
${ }^{1,3,7}$ Professor, ${ }^{2,8}$ Associate Professor, ${ }^{4,5}$ Postgraduate Student ${ }^{6}$ Postdoctoral Student

${ }^{1}$ Department of Endodontics, Dentalis, Redentor School Itaperuna, Rio de Janeiro, Brazil

2-5,7,8 Department of Restorative Dentistry, Araraquara Dental School, UNESP-Univ Estadual Paulista, Araraquara, São Paulo, Brazil

${ }^{6}$ Department of Physiology and Pathology, Araraquara Dental School, UNESP-Univ Estadual Paulista, Araraquara, São Paulo, Brazil

Corresponding Author: Milton Carlos Kuga, Associate Professor, Faculdade de Odontologia de Araraquara, FOArUNESP, Departamento de Odontologia Restauradora - $3^{\circ}$ andar. Rua Humaitá 1680 Centro CEP 14801-903, Araraquara São Paulo, Brazil, e-mail: miltoncarloskuga@hotmail.com
}

Keywords: Broken, Fracture, Endodontic, Instruments, retrieval, Separated.

How to cite this article: do Carmo Monteiro JC, Kuga MC, Dantas AAR, Jordão-Basso KCF, Keine KC, Ruchaya PJ, Faria G, de Toledo Leonardo R. A Method for retrieving Endodontic or Atypical Nonendodontic separated Instruments from the Root Canal: A Report of Two Cases. J Contemp Dent Pract 2014;15(6):770-774.

\section{Source of support: Nil}

Conflict of interest: None declared

\section{INTRODUCTION}

The presence of separated instrument within the root canals in well-treated cases without periapical lesion does not reduce the success rate of endodontic treatment. ${ }^{1}$ It is questionable in this situation whether the fragment should be removed or only bypassed and included within the root canal obturation. However, other cases is recommended its removal because the fragment presence will negatively influence the success prognosis of endodontic treatment. ${ }^{2}$

If bypass the instrument fragment is impossible, the cleaning and shaping of the apical segment from the root canal are damaged, and it is not possible to conduct an adequate chemical-mechanical apical preparation. In order to solve these cases, many removal techniques have been suggested with success rate of approximately $83 \%$ of cases. ${ }^{3}$ However, the conventional methods may cause detrimental effects on the dentinal structure leading to a radicular fracture resistance reduction. ${ }^{4}$

When the instrument fragment is located at the straight segment of the root canal, the removal by ultrasonic technique is effective in approximately $80 \%$ of cases. ${ }^{5}$ However, when only one fragment segment is retained within the root canal, a new fracture from free coronal portion may occur due to the high intracanal ultrasonic vibration frequency.

On the contrary, techniques that use special devices such as Masseran and Endo Extractor may excessively wear radicular dentin. This is because such techniques require the prior use of caliber burs for the devices 
adaptation within the root canal and is only recommended for straight root canals. ${ }^{6-8}$

In order to prevent root dentin wear, the use of electrochemical methods for dissolution of the stainless and nickel-titanium separated instruments inside the root canals have been suggested. ${ }^{9}$ However, these are at preliminary stages requiring further evaluation particularly regarding the effect on the root dentin.

The use of a modified 18-gauge needle and cyanoacrylate glue has been proposed to retrieve a separated NiTi instrument from the mesiolingual canal of a mandibular first molar. ${ }^{10}$ The limitations of this technique includes obstruction of the root canal since there is a requirement of the cyanoacrylate glue within the modified needle and the set reposition inside the canal engulfing the coronal end of the separated instrument. Furthermore, this technique has a high degree of difficulty perform, since the separated instrument seizure in the modified needle is hard and may move within it.

Suter ${ }^{11}$ proposed the use of short piece of stainlesssteel tube pushed over the exposed end of the separated instruments and a Hedström file pushed in a clockwise turning motion through the tube to wedge between the tube and end of the instrument. Thus, effectively enabling the three objects to be removed coronally using relatively high forces. To date, this is the only one successful case reported regarding separated instrument removal from the root canal however the sequence treatment performance was not clearly described.

Therefore, the aim of this study is to present two successful clinical cases of retrieving an endodontic and a nonendodontic separated instrument associated with a stainless-steel prepared needle associated with a K-file adapted inside it. The removal of instruments were unsuccessful in both cases when previously treated by the ultrasonic technique.

\section{CASE REPORTS}

\section{Case 1}

A 45-year-old male patient was referred to endodontic treatment in the mandibular left second premolar. Clinical evaluation showed no edema and sinus tract at alveolar mucous. The coronal access was restored with temporary cement. Radiographic evaluation showed separated endodontic instrument (McSpadden guttacondenser) within the root canal, occupying the entire length of the root canal (Fig. 1A). The accident occurred at intracanal medication with calcium hydroxide placement moment, inadvertently inserted with gutta-condenser (Dentsply, Ballaigues, Switzerland). The patient left the treatment after the complication and returned to the treatment after 5 years.
After the temporary restorative material removal, the pulp chamber was irrigated with $10 \mathrm{ml}$ of $2.5 \%$ sodium hypochlorite (Asfer, São Caetano do Sul, SP, Brazil). Initial exploration was performed with \#15 K-file (Maillefer, Ballaigues, Switzerland) at cervical third of the root canal, confirming the presence of the separated instrument. Oscillatory movement enabled to overcome only the coronal segment from the fragment. A \#25 ultrasonic tip (Helse, Ribeirão Preto, SP, Brazil) was activated laterally to this segment for 30 seconds and the retrieval was performed at coronal direction with a \# $25 \mathrm{H}$-file (Maillefer, Ballaigues, Switzerland) with pull-on movement.

After removal attempts, a new fracture of the coronal segment from the separated endodontic instrument occurred at the middle third of the root canal. A prepared stainless-steel hypodermic needle (BD, São Paulo, SP, Brazil), gauge 21, was adapted inside the root canal and fitted the coronal end separated instrument (Fig. 1B). Previously to its removal, a wear between the separated instrument and the root dentin was performed using \# 15 K-file. Using oscillatory movements approximately $2 \mathrm{~mm}$ in an apical direction, the stainless-steel needle was inserted inside the root canal (Fig. 1C).

Proceeding the appropriate adaptation within the root canal and the free portion of the separated instrument, \#25 K-file was pushed in a clockwise turning motion through the needle to wedge between the needle and coronal end of the separated instrument, until the K-file could not move in the apical direction. A very tight connection was formed between the K-file instrument needle and separated, by pulling on the handle of K-file, the set can be subsequently be readily withdrawn from the root canal (Fig. 1D). A new radiographic confirmed the removal of a gutta-condenser fragment (Fig. 1E). Later endodontic treatment was performed after tooth isolation and the root canal obturated with gutta-percha and epoxy-based sealer (Sealer 26, Dentsply, RJ, Brazil), using the lateral condensation technique (Fig. 1F).

\section{CASE 2}

A 12-year-old male patient was referred for endodontic treatment in the maxillary left central incisor. The patient reported that after the diagnosis of an endodontic abscess, the tooth was submitted to coronary access, detoxification of the root canal content, intracanal medication and temporary restoration. However, the root canal treatment was not completed. After 12 months, the patient sought treatment, upon examination and it was observed that the temporary restoration was absent and the root canal was exposed to the oral environment. This consequently allowed any food could enter into the coronal access causing discomfort to the patient. Thus, in order to solve 

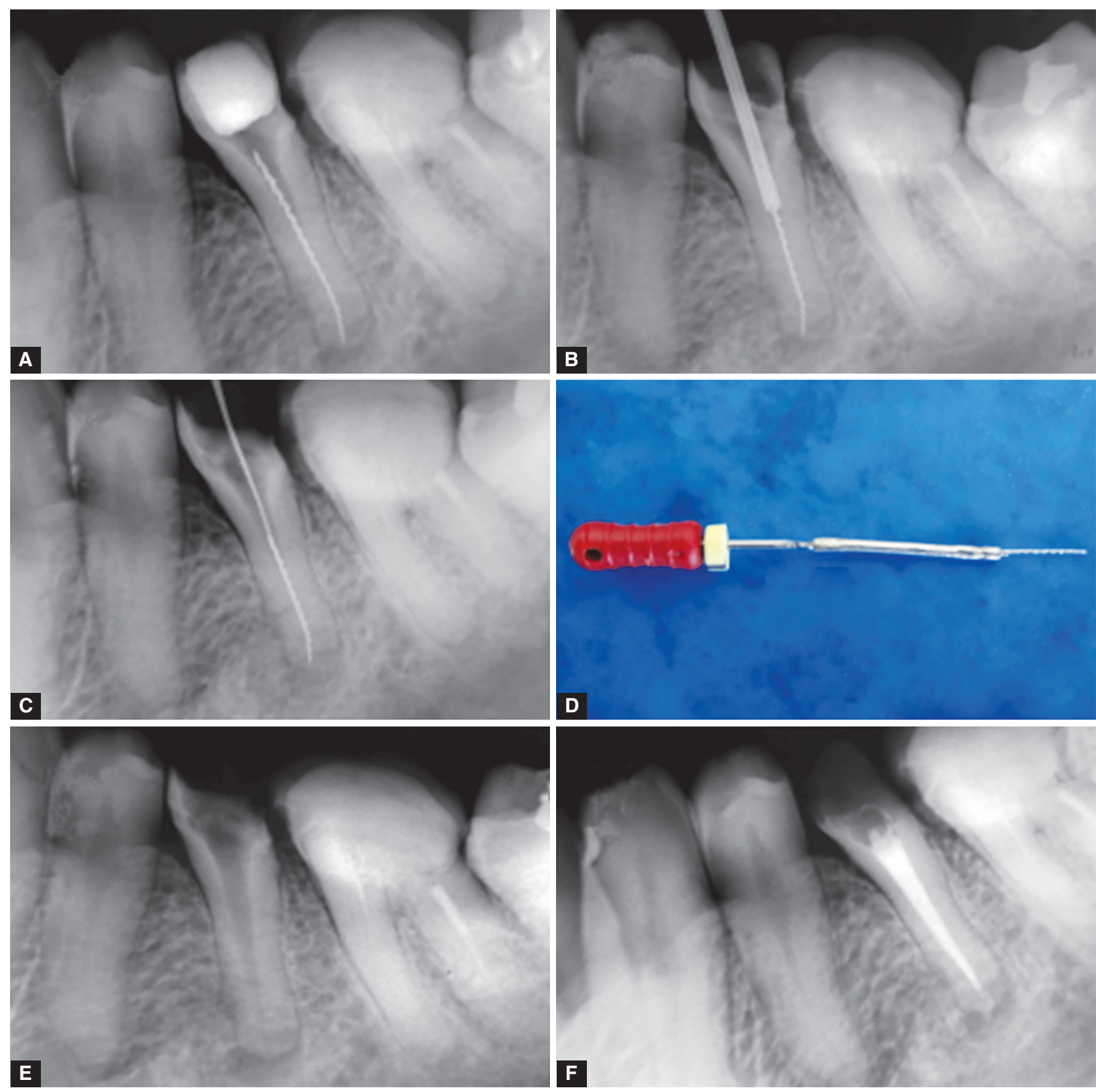

Figs 1A to F: (A) Presence of the gutta-condenser inside the radicular canal from mandibular left second premolar, (B) adaptation of the coronal end of a separated instrument in a prepared stainless-steel needle, (C) wear between root dentin and the separated instrument, (D) gutta-condenser removed with a \#25K-file, (E) root canal without gutta-condenser and (F) root canal obturation

this problem the patient used to remove this debris with a sewing needle. After trying to remove food debris, the patient made a sudden lever movement, causing the separation of nonendodontic instrument within the root canal, verified by radiographic analysis (Fig. 2A).

At clinical treatment, copious irrigation with sodium hypochlorite solution 2.5\% (Asfer, São Caetano do Sul, SP, Brazil) was performed. A \#25 ultrasonic tip (Helse, Ribeirão Preto, SP, Brazil) was adapted between the root dentin and coronal needle segment and activated for 30 seconds. However, the fragment removal from the root canal was not possible, once it was displaced in the apical direction (Fig. 2B). Therefore, the removal option was identical to that described in case 1 . A prepared stainless-steel needle, gauge 21 , was fitted to the coronal end of the fractured needle. The \#25 K-file was positioned between the inner wall of the stainless-steel needle and the needle fragment, the whole set was coronally tractioned, removing the atypical nonendodontic separated instrument (Figs 2C and D).

Following the complete removal, the chemicalmechanical preparation of the root canal was performed and intracanal medication with calcium hydroxide was placed. However, the patient never returned back for the clinical case conclusion.

\section{DISCUSSION}

The present study described two successful cases of the separated instrument removal from the root canal, which could not be removed by the ultrasonic technique and 

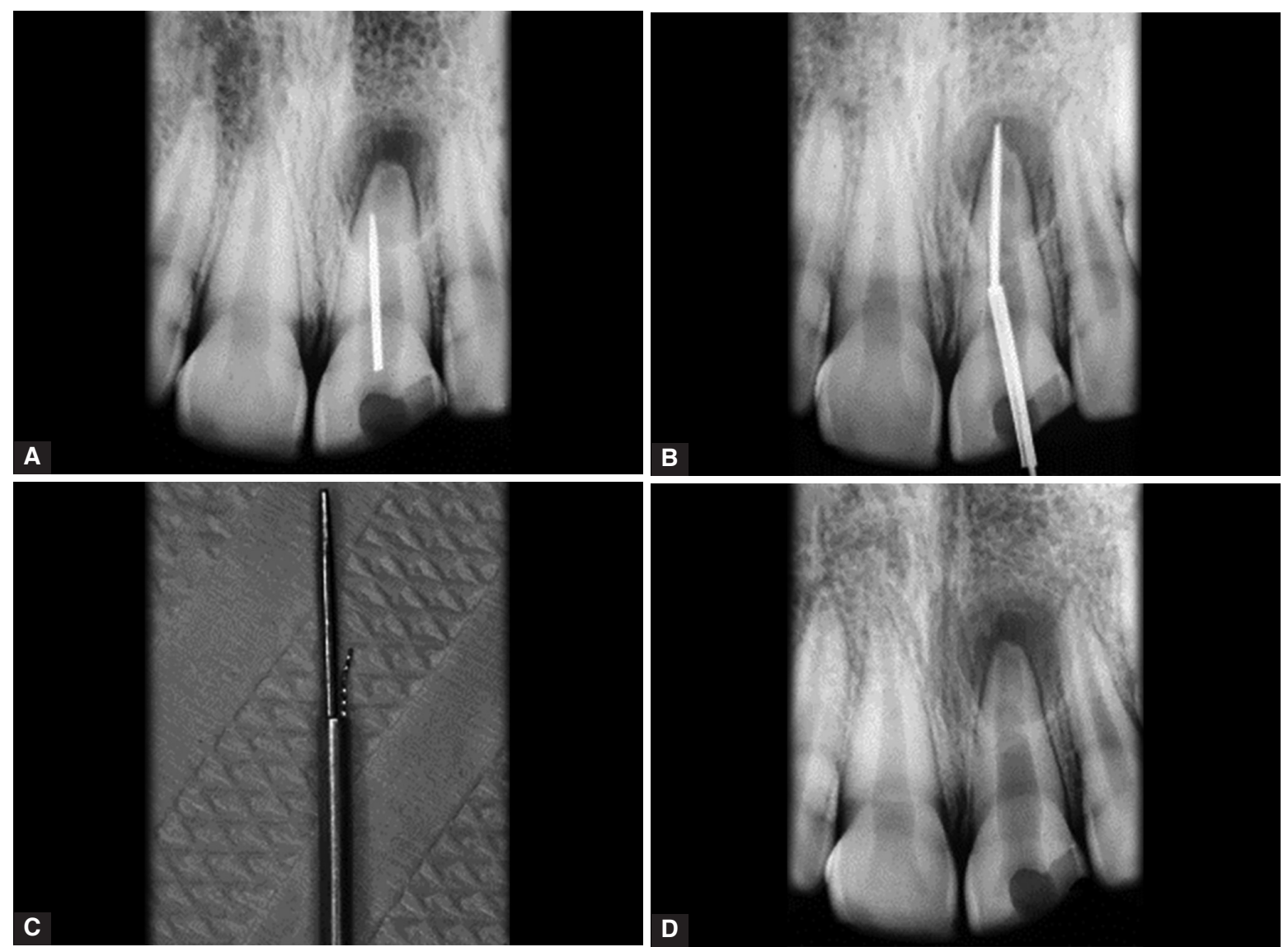

Figs 2A to D: (A) atypical nonendodontic separated instrument in the left central maxillary central incisor, (B) apical displacement of the separated instrument after ultrasonic use and adaptation in a prepared stainless-steel needle, $(C)$ separated instrument removed with a \# 25K-file and (D) root canal without the atypical separated instrument

by coronal traction with \#25 H-file. This was resolved by novel method using a prepared stainless-steel hypodermic needle associated with \#25 K-file.

Several methods have been described regarding the removal of separated instruments from root canal. However, many of these techniques cause excessive radicular dentin removal and may promote side effects such as radicular resistance fracture reduction. ${ }^{4}$ In both clinical cases, the use of ultrasonic treatment followed by a coronal traction attempt with \#25 H-file was ineffective. The first case presented a new fracture in gutta-percha condenser near the middle third of the root canal. The second case displayed the apical displacement of the separated nonendodontic instrument (needle).

The use of endo extractor or masseran kit was avoided because they require special devices and seizure of the coronal end from the separated instrument within its devices is difficulty. ${ }^{12}$ Another negative point is that these systems require prior root canal preparation with special burs, promoting an excessive wear of the dentin and/or root perforation, especially after $7.5 \mathrm{~mm}$ depth in the mesial root of the mandibular molars. ${ }^{13}$ The success rate of separated instrument removal with these systems is lower $(47.6 \%)$ than the ultrasonic $(95.2 \%)$ or than the conventional method $(80.9 \%) .{ }^{14}$
On the contrary, the modified hypodermic needle allows appropriate set adaptation with less wear of the root dentin. ${ }^{15,16}$ The separated instrument retention inside the needle is a critical factor for the technique success. The cyanoacrylate does not allow adequate instrument seizure inside the stainless steel needle. This impedes a strong traction movement and hampers the instrument removal mainly at curved root canals. ${ }^{10}$

When the cyanoacrylate technique had failed, $\mathrm{H}$-file may be pushed in a clockwise turning motion through the stainless-steel to wedge the coronal part of the fragment and the needle's inner wall. ${ }^{3,16}$ However, due to its structural feature, there is a risk of another instruments separation as observed in case 1 during interlocking between the fragment and the H-file. Moreover, due to the lower angle of the active blade in relation the instrument long axis, the K-file provides a greater length penetration between the fragment and the inner wall of the needle. Consequently, this improves the set seizure facilitating the pull on of the root canal depicted in Figure 2A. The greater length penetration of the endodontic file between the separated instrument and the inner wall of the prepared stainless-steel needle helps the coronal removal especially when the fragment is smooth, as described in case 2. 
Therefore, the use of prepared hypodermic surgical needles is recommended in unsuccessful cases of separated instruments removal with ultrasonic, with an advantage of less root dentin removal. The fragment removal with the K-file instead of $\mathrm{H}$-file, as reported in these clinical cases warrants a greater seizure length and adaptation improving the separated instrument removal technique.

\section{CONCLUSION}

A stainless-steel prepared hypodermic surgical needle with \#25 K-file inside it can be used to remove endodontic or nonendodontic separated instrument within the root canal with minimally invasive procedures, when the ultrasonic and/or coronal pull on with a \# $25 \mathrm{H}$-file technique are unsuccessful.

\section{CLINICAL SIGNIFICANCE}

The methods for retrieving separated instruments from root canal are difficult and destructive procedures. The present case describes a simple method to solve this problem.

\section{REFERENCES}

1. McGuigan MB, Louca C, Duncan HF. Clinical decisionmaking after endodontic instrument fracture. Br Dent J 2013a Apr;214(8):395-400.

2. McGuigan MB, Louca C, Duncan HF. The impact of fracture endodontic instruments on treatment outcome. Br Dent J 2013b Mar;214(6):285-289.

3. Suter B, Lussi A, Sequeira P. Probability of removing fractured instruments from root canals. Int Endod J 2005 Feb;38(2): 112-123.

4. Romeed SA, Dunne SM. The impact of fractured endodontic file removal on vertical root fracture resistance: three-dimen- sional finite element analysis. Eur J Prosthodont Restor Dent 2012 Jun;20(2):86-91.

5. Shahabinejad H, Ghassemi A, Pishbin L, Shahravan A. Success of ultrasonic technique in removing fractured rotary nickel-titanium endodontic instruments from root canals and its effect on the required force for root fracture. J Endod 2013 Jun;39(6):824-828.

6. Thirumalai AK, Sekar M, Mylswamy S. Retrieval of a separated instrument using Masserann technique. J Conserv Dent 2008 Jan;11(1):42-45.

7. Vivekananda Pai AR, Mir S, Jain R. Retrieval of a metallic obstruction from the root canal of a premolar using Masserann technique. Contemp Clin Dent 2013 Oct;4(4):543-546.

8. Choksi D, Idnani B, Kalaria D, Patel RN. Management of an intracanal separated instrument: a case report. Iran Endod J 2013 Fall;8(4):205-207.

9. Aboud LR, Ormiga F, Gomes JA. Electrochemical induced dissolution of fragments of nickel-titanium endodontic files and their removal from simulated root canals. Int Endod J 2014 Feb;47(2):155-162.

10. Andrabi SM, Kumar A, Iftekhar H, Alam S. Retrieval of a separated nickel-titanium instrument using a modified 18-guage needle and cyanoacrylate glue: a case report. Restor Dent Endod 2013 May;38(2):93-97.

11. Suter B. A new method for retrieving silver points and separated instruments from root canals. J Endod 1998 Jun; 24(6):446-448.

12. Gettleman BH, Spriggs KA, ElDeeb ME, Messer HH. Removal of canal obstructions with the Endo Extractor. J Endod 1991 Dec;17(12):608-611.

13. Yoldas O, Oztunc H, Tinaz C, Alparslan N. Perforation risks associated with the use of Masserann endodontic kit drills in mandibular molars. Oral Surg Oral Med Oral Pathol Oral Radiol Endod. 2004 Apr;97(4):513-517.

14. Gencoglu N, Helvacioglu D. Comparison of the different techniques to remove fractured endodontic instruments from root canal systems. Eur J Dent 2009 Apr;3(2):90-95.

15. Eleazer PD, O'Connor RP. Innovative uses for hypodermic needles in endodontics. J Endod 1999 Mar;25(3):190-191.

16. Madarati AA, Hunter MJ, Dummer PM. Management of intracanal separated instruments. J Endod 2013 May;39(5): 569-581. 